\title{
Impact of preventive care orientation on caries status among preschool children
}

\author{
Hisham Yehia El Batawi ${ }^{1}$, Kausar Sadia Fakhruddin ${ }^{1}$
}

Correspondence: Dr. Hisham Yehia El Batawi

Email: helbatawi@sharjah.ac.ae

\author{
'Department of Preventive and Restorative \\ Dentistry, College of Dental Medicine, University of \\ Sharjah, Sharjah 27272, United Arab Emirates
}

\section{ABSTRACT}

Objective: This study aims to study the impact of preventive care orientation given to caregivers of child daycare centers on their knowledge and on the prevalence of early childhood caries (ECC) among preschool children. Materials and Methods: Caregivers of twenty child daycare centers in Emirate of Sharjah were interviewed and 435 children attending these centers were surveyed for decayed missing filled teeth $(\mathrm{dmft})$. The sample data were analyzed using $t$-tests and one-way ANOVA to assess the statistical significance of the differences in $\mathrm{dmft}$ score found between groups. Results: No significant correlation was found between $\mathrm{dmft}$ scores and family income of urban or rural centers, mothers' level of education, mothers' employment status in public centers, and frequency of dental visits. There was a significant correlation between dmft scores and mothers' employment status in private centers with the lowest scores among children of working mothers. High caries rates were observed in children attending private daycare centers where sweetened milk, juices, and snacks were served more frequently. There was a significant difference between private and public centers in caregivers' level of knowledge regarding oral health in favor of the latter. Low dmft scores were found to be associated with high level of knowledge of caregivers in public centers. Conclusions: Children are more likely to develop ECC if their caregivers are lacking knowledge or regular provision of preventive care orientation. This makes caregivers and school teachers better candidates for oral health education programs than parents.

Key words: Early childhood caries, health education, preschool

\section{INTRODUCTION}

Early childhood caries (ECC) is a serious health problem and one of the most common types of dental caries affecting infants and toddlers with a prevalence ranging from $34 \%$ to $56 \%$ in children aged 2-3 years. ${ }^{[1,2]}$ ECC is defined as the presence of one or more decayed lesions (cavitated or not), missing (due to caries), or filled tooth surfaces in any primary tooth in a child 36 months of age or younger. When a 3-year-old child has a decayed, missing, filled teeth index (dmft) score of 4 or more, then the case is defined as severe ECC. The consequences of ECC are not only confined to

\begin{tabular}{|l|l|}
\hline \multicolumn{3}{|c|}{ Access this article online } \\
\hline Quick Response Code: & \\
\hline
\end{tabular}

damaging primary teeth, but they also may lead to more widespread health issues where affected children with ECC may grow at a lower rate than caries-free infants. Furthermore, it was reported that ECC is associated with underweight and disinclination to eating. ${ }^{[3]}$

Like other types of dental caries, ECC has a multifactorial nature of etiology. The etiological factors include the use of baby bottles and/or breasts as pacifiers, frequent and prolonged exposure of primary teeth to fermentable sugars and beverages,

This is an open access article distributed under the terms of the Creative Commons Attribution-NonCommercial-ShareAlike 3.0 License, which allows others to remix, tweak, and build upon the work non-commercially, as long as the author is credited and the new creations are licensed under the identical terms.

For reprints contact: reprints@medknow.com

How to cite this article: El Batawi HY, Fakhruddin KS. Impact of preventive care orientation on caries status among preschool children. Eur J Dent 2017;11:475-9.

DOI: 10.4103/ejd.ejd_170_17 
the physiologic behavior of ECC microflora, age of the child, environmental factors, and awareness of the child's caregivers. ${ }^{[4]}$

Oral health surveys are important tools to obtain information about the prevalence, extent, and the forementioned causative factors of ECC. This is very essential to develop successful policies and programs in preventing and managing ECC. The most commonly used criteria for surveying dental caries are the criteria set by the World Health Organization (WHO). The advantage of WHO criterion includes ease of mastering, its practicality, the high level of agreement among examiners, and the possibility of comparing the results of different populations worldwide. ${ }^{[5]}$ For effective strategic planning of caries prevention programs, it is important to understand the social value that caregivers and communities ascribe to primary teeth. ${ }^{[6]}$ This understanding may help in identifying at-risk children who deserve to be targeted by preventive oral health programs.

The aim of this work is to study the impact of preventive care orientation given to caregivers of child daycare centers on their knowledge and on the prevalence of ECC among preschool children using WHO criteria for assessment.

\section{MATERIALS AND METHODS}

A total of twenty child daycare centers in Emirate of Sharjah were surveyed through University of Sharjah Outreach Program. Ten centers were public, i.e., government sponsored, and ten were private. All public daycares in the Emirates of Sharjah are registered and run by the Ministry of Education, United Arab Emirates (UAE) while all private daycares are registered and licensed by the Ministry of Education, Government of Sharjah, UAE, and they are authorized to function under private administration following Sharjah government supervision. The twenty centers provided a pool of 449 children who were invited to participate. The study was conducted on 435 children after excluding children who did not return consent forms and those who lacked cooperative behavior, accordingly, 216 children belonged to public daycare centers while 219 were attending private centers participated in the study.

The data were collected during routine outreach program of the University of Sharjah. Information sheets were sent before these visits to the daycare facilities (public and private daycares). Consent for screening was obtained from the parents of every participating child. Reference UoSId-10725.

The staff (caregivers) attending the centers were interviewed where a thorough explanation of the aim and nature of the work was provided. That was followed by questionnaires targeting detailed information about each child's dietary habits, oral hygiene habits, frequency of dental visits, and socioeconomic status. The preventive care awareness, knowledge, and attitudes of the caregivers were also assessed.

One investigator carried out the intraoral examination on all children using the WHO criteria mentioned in oral health surveys: Basic methods 2013. ${ }^{[7]}$ The tools for examination were limited to disposable mirrors and torches of light on ordinary chairs. No radiographic examination was carried out due to lack of radiation safety setup in the centers.

Intrainvestigator calibration was attempted using Cohen's Kappa coefficients where $10 \%$ of the sample was selected for reexamination. The sample data were analyzed using $t$-tests and one-way ANOVA to assess the statistical significance of the differences in $\mathrm{dmft}$ score found between groups. The child's dmft score as dependent and all independent variables were entered into model. Variables with no statistical significance were removed using backward stepwise procedure. The final model contains only those variables with statistical significance. The statistical significance was set at 0.05 for all tests.

\section{RESULTS}

A total of 449 children were invited to participate for dental screening; in three cases (one from public and 2 from private daycare), the consent forms were not returned, and eleven uncooperative children ( 3 from public and 8 from private daycare) were excluded from the study. Of $n=435$ children screened from 10 public and 10 private daycare centers, $n=$ 216 , children were attending public daycare centers located in urban and rural areas and $n=219$ were attending private daycare centers in urban areas of Sharjah, United Arab Emirates. For diagnosis of dental status, the value of Kappa statistic was 0.94. The mean age of the screened children was $1.2 \pm 3.6$ years. Approximately, over half $(n=238,55 \%)$ of them were boys. They found no statistically significant difference between the mean dmft score of the boys and of girls enrolled either in private or public daycare centers. 
The proportion of children with mean $\mathrm{dmft}=0$ was only $23 \%$ in private daycare versus $78 \%$ observed in public daycares of urban and rural areas. Untreated dental decay contributed over $55 \%$ of the mean $\mathrm{dmft}$ score of children in private daycare. The mean number of filled (ft) deciduous teeth contributes $3.6 \pm 4.2$ in children attending private daycares in urban areas. Children of different nationalities (residents) enrolled in private daycares had a higher mean $\mathrm{dmft}$ score than that of nationals (citizens) enrolled in government-run daycares (8.1 vs. $0.8, P=0.001)$, Table 1 .

All government run public daycare centers serve traditional foods to their children. The foods were prepared in the facilities own kitchen. In addition, all public daycares in urban and rural areas have structured health care services for their registered children, Figure 1.

Children attending government-run public daycares showed significantly $(P=0.001)$ less caries prevalence, where there is availability of preventive oral health orientations for caregivers by the Ministry of Health, Table 2. Moreover, children from private daycares whose mothers are mostly homemakers showed significantly higher $\mathrm{dmft}(P<0.05)$ compared to children with working moms.

Concerning dietary habits (frequency of fruit juices and flavored milk and snacks) of children attending private daycares showed significantly higher mean dmft score compared to that of children from public daycares who follow controlled and structured diet plan. Furthermore, in the bivariate analysis, dental visit was found to have no statistically significant association with child's dental health status, Table 3.

Table 4 illustrates lack of preventive care awareness of the caregivers and lack of structured meals and snacks plan at the daycare facilities were associated with high dmft scores in children attending private daycare centers. No correlation was found between high socioeconomic status and dmft scores.

\section{DISCUSSION}

It is generally more tedious to assess the benefits of health education than of direct therapies, ${ }^{[8]}$ and the current study is no exception. The results of our study are in agreement with Jose and King, $2003^{[9]}$ that the noninvasive nature of the investigation resulted in high participation rate $(96.88 \%)$. The same study in addition to a study by Chan et al. in $2002^{[10]}$ reported

\begin{tabular}{|c|c|c|c|}
\hline & $n$ & $\mathrm{dmft}>0(\%)$ & $\mathrm{dmft} \pm \mathrm{SD}$ \\
\hline Public day care - urban area & 117 & & \\
\hline \multicolumn{4}{|l|}{ Gender } \\
\hline Boys & 45 & 3.2 & $0.4 \pm 1.1$ \\
\hline Girls & 72 & 5 & $0.6 \pm 1.5$ \\
\hline \multicolumn{4}{|l|}{ Nationality } \\
\hline Emirati (citizens) & 117 & 8.2 & \\
\hline Other nationalities (residents) & 0 & 0 & \\
\hline Public day care - rural area & 99 & & \\
\hline \multicolumn{4}{|l|}{ Gender } \\
\hline Boys & 48 & 5.3 & $1.3 \pm 2.2$ \\
\hline Girls & 51 & 8.2 & $0.9 \pm 2.8$ \\
\hline \multicolumn{4}{|l|}{ Nationality } \\
\hline Emirati (citizens) & 99 & 13.5 & \\
\hline Other nationalities (residents) & 0 & 0 & \\
\hline Private day care - urban area & 219 & & \\
\hline \multicolumn{4}{|l|}{ Gender } \\
\hline Boys & 145 & 36.2 & $8.6 \pm 10.2$ \\
\hline Girls & 74 & 31.9 & $7.3 \pm 9.7$ \\
\hline \multicolumn{4}{|l|}{ Nationality } \\
\hline Emirati (citizens) & 8 & 9.1 & \\
\hline Other nationalities (residents) & 211 & 68.1 & \\
\hline
\end{tabular}

dmft: Decayed missing filled teeth, SD: Standard deviation

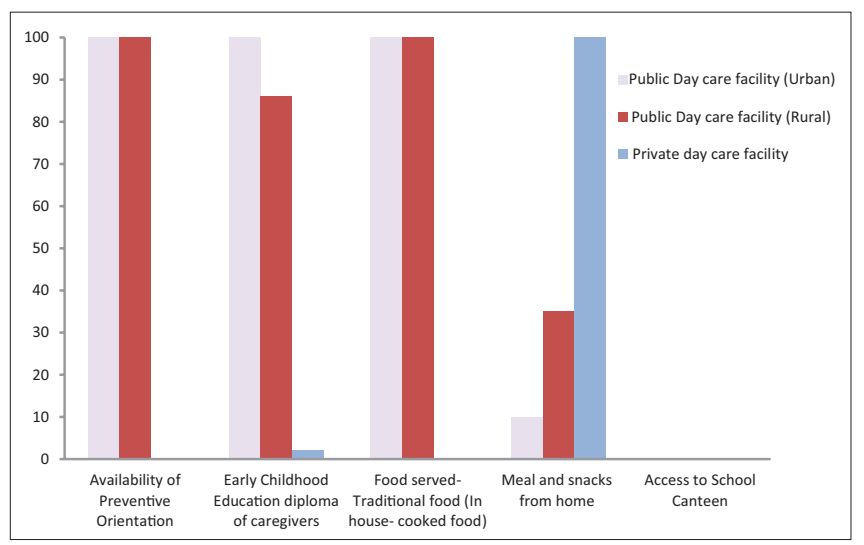

Figure 1: Oral health services, sociocultural and environmental risk factors in dental caries at public and private daycare facilities

inverse relationship between socioeconomic status of parents and dmft scores; however, our results did not show such relation. This could be related to unique socioeconomic factors related to the gulf countries (Gulf Cooperation Council [GCC] countries) where income alone does not accurately indicate socioeconomic level.

The significant difference in number of treated teeth between expatriates versus nationals with expatriates having more untreated carious teeth reflects a difference in access of dental care and possibly insurance coverage between the two groups. The 


\begin{tabular}{|c|c|c|c|}
\hline Risk factors & $n(\%)$ & $\mathrm{dmft} \pm \mathrm{SD}$ & $\boldsymbol{P}$ \\
\hline \multicolumn{4}{|l|}{ Oral health services } \\
\hline \multicolumn{4}{|l|}{ Public day care - urban/rural area } \\
\hline Availability of preventive orientation & $216(100)$ & $0.5 \pm 1.3$ & $0.001^{* *}$ \\
\hline \multicolumn{4}{|c|}{ Private day care - urban area } \\
\hline Availability of preventive orientation & $0(0)$ & $8.0 \pm 9.2$ & \\
\hline \multicolumn{4}{|l|}{ Sociocultural risk factors } \\
\hline \multicolumn{4}{|l|}{ Family income } \\
\hline AED $\leq 100,000$ & $23(10.6)$ & $1.4 \pm 2.1$ & \\
\hline AED $>100,000$ & $193(89.4)$ & $0.9 \pm 1.5$ & \\
\hline \multicolumn{4}{|l|}{ Family income } \\
\hline$A E D \leq 100,000$ & $39(17.8)$ & $6.4 \pm 8.1$ & \\
\hline AED $>100,000$ & $180(82.2)$ & $7.2 \pm 8.7$ & \\
\hline \multicolumn{4}{|l|}{ Mother's highest level of education } \\
\hline High school & $117(54.1)$ & $1.3 \pm 1.33$ & \\
\hline College/university & $99(45.8)$ & $0.8 \pm 1.07$ & \\
\hline Private day care - urban area & & & NS \\
\hline \multicolumn{4}{|l|}{ Mother's highest level of education } \\
\hline High school & $47(21.5)$ & $6.7 \pm 1.23$ & \\
\hline College/university & $172(78.5)$ & $5.8 \pm 1.77$ & \\
\hline \multicolumn{4}{|l|}{ Mother's employment status } \\
\hline Working mothers & $85(39.4)$ & $0.8 \pm 2.3$ & \\
\hline Homemakers & $131(60.6)$ & $2.7 \pm 3.6$ & \\
\hline \multicolumn{4}{|l|}{ Private day care - urban area } \\
\hline \multicolumn{4}{|l|}{ Mother's employment status } \\
\hline Working mothers & $96(43.8)$ & $4.1 \pm 5.7$ & $\leq 0.05$ \\
\hline Homemakers & $123(56.1)$ & $8.5 \pm 9.3$ & \\
\hline
\end{tabular}

finding that high numbers of untreated teeth increases with low economic capability is in agreement with Casamassimo et al., 2009. ${ }^{[11]}$

In our study, there was a significant difference in the overall dmft scores between expatriate children versus Emirati children in favor of the latter. This finding may be attributed to nutritional habits as it was verified by our investigation that Emirati children especially in rural areas have a tendency to consume traditional foods whereas expatriate children tend to consume more fast food and sweetened snacks.

The impact of nutritional habits on caries incidence was furtherly proved by our results which showed lower mean $\mathrm{dmft}$ scores among children attending public daycare centers which served controlled and structured meals prepared at in-house kitchen facility. On the other hand, higher $\mathrm{dmft}$ mean was observed

\begin{tabular}{|c|c|c|c|}
\hline Risk factors & $n(\%)$ & $\mathrm{dmft} \pm \mathrm{SD}$ & $P$ \\
\hline \multicolumn{4}{|l|}{ Dietary habits } \\
\hline $\begin{array}{l}\text { Frequency of flavored milk/juices } \\
\text { served (in between meals) }\end{array}$ & & & $<0.05$ \\
\hline Public daycare facility & $216(100)$ & $0.7 \pm 1.2$ & \\
\hline Private daycare facility & $219(100)$ & $7.9 \pm 8.4$ & \\
\hline Meals and snacks & & & $<0.02$ \\
\hline \multicolumn{4}{|l|}{ Public daycare facility } \\
\hline $\begin{array}{l}\text { Meals/snacks prepared at the } \\
\text { daycare facility }\end{array}$ & $216(100)$ & $0.4 \pm 1.5$ & \\
\hline \multicolumn{4}{|l|}{ Private daycare facility } \\
\hline $\begin{array}{l}\text { Meals/snacks from home } \\
\text { (private daycare facility) }\end{array}$ & $219(100)$ & $6.8 \pm 7.3$ & \\
\hline \multicolumn{4}{|l|}{ Use of dental services } \\
\hline \multicolumn{4}{|l|}{ Public day care - urban/rural area } \\
\hline Yes & $8(3.7)$ & $1.2 \pm 2.3$ & NS \\
\hline No & $208(96.3)$ & $0.4 \pm 0.9$ & \\
\hline \multicolumn{3}{|l|}{ Private day care - urban area } & \\
\hline Yes & $24(10.9)$ & $5.6 \pm 7.2$ & NS \\
\hline No & $195(89.1)$ & $6.9 \pm 8.2$ & \\
\hline
\end{tabular}

among children attending private centers who used to bring sweetened snacks from home.

Many studies agree on the assumption that low maternal level of education is associated with high $\mathrm{dmft}$ scores in preschool children. ${ }^{[9,12,13]}$ This might be attributed to the lack of enough knowledge about oral health among uneducated mothers. ${ }^{[14]}$ However, our results did not show such correlation which is in agreement with Schroth et al., in 2005. ${ }^{[15]}$ This could be an expression of the multifactorial nature of caries etiology where no single etiological factor can be blamed for the disease.

In the current study, there was a significant difference in $\mathrm{dmft}$ scores between children whose mothers are working versus children of homemakers with the latter having higher caries scores. This finding is in agreement with Kim Seow in 2012. ${ }^{[16]}$ These results support other studies that found predictable relationships between locus of control belief and oral health status. According to this theory, individuals (working mothers in our case) who believe they have control over their own oral health are more likely to adopt good oral health practices compared to those who believe their dental health is controlled by external factors. ${ }^{[17]}$

The argument relating mothers' level of education, work, and socioeconomic status to their children's 


\begin{tabular}{|c|c|}
\hline Risk factors & $\begin{array}{l}\text { Odds ratio } \\
(95 \% \mathrm{Cl})\end{array}$ \\
\hline \multicolumn{2}{|l|}{ Availability of preventive orientation } \\
\hline Public daycare facility & $0.4(0.02-0.07)^{*}$ \\
\hline Private daycare facility & $2.9(1.17-3.26)^{\star *}$ \\
\hline \multicolumn{2}{|l|}{ Early childcare education diploma } \\
\hline Public daycare facility & $0.3(0.01-0.04)$ \\
\hline Private daycare facility & $1.9(1.60-2.12)^{*}$ \\
\hline \multicolumn{2}{|l|}{ Dental education of caregivers } \\
\hline Public daycare facility & $0.2(0.02-1.01)$ \\
\hline Private daycare facility & $3.8(1.15-4.07)^{\star *}$ \\
\hline \multicolumn{2}{|l|}{$\begin{array}{l}\text { Frequency of flavored milk/juices } \\
\text { served (in between meals) }\end{array}$} \\
\hline Public daycare facility & $1.2(0.85-1.29)$ \\
\hline Private daycare facility & $2.5(1.09-2.86)$ \\
\hline \multicolumn{2}{|l|}{ Meals and snacks } \\
\hline $\begin{array}{l}\text { Meals/snacks prepared at the } \\
\text { daycare facility (public day care) }\end{array}$ & $0.8(0.02-1.03)$ \\
\hline $\begin{array}{l}\text { Meals/snacks from home } \\
\text { (private daycare facility) }\end{array}$ & $3.2(2.83-4.65)^{*}$ \\
\hline
\end{tabular}

oral health may suggest that parents may not be the ideal target for oral health education programs compared to daycare staff and school teachers. This is confirmed by our results which correlated high $\mathrm{dmft}$ scores with lack of provision of preventive care orientation to caregivers in private centers. On the contrary, it was demonstrated in public daycare centers that the regular provision of preventive care orientation to caregivers was associated with low $\mathrm{dmft}$ mean score which highlights the importance of periodic reinforcement of health education messages to counteract the effect of fading over time and to transform knowledge into actual reduction in caries incidence. These results are in agreement with the work done by Petersen et al. in 1990[18] and Wyne et al., in 2002. ${ }^{[19]}$

Some of the limitations of the current study include obtaining information related to parents and home dietary habits from center caregivers and not directly from mothers. In the Gulf States (GCC), it is common that the home caregiver is not the mother but a domestic helper who is recruited from abroad. This may create a cultural gap which may affect the reliability of data.

\section{CONCLUSIONS}

Children are more likely to develop ECC if their caregivers are lacking knowledge or regular provision of preventive care orientation. This makes caregivers and school teachers better candidates for oral health education programs than parents.

Organized community effort to control the availability of sweetened snacks and to adjust dietary habits may have a positive impact on $\mathrm{dmft}$ mean scores on preschool children.

\section{Financial support and sponsorship Nil.}

\section{Conflicts of interest}

There are no conflicts of interest.

\section{REFERENCES}

1. Douglass JM, Tinanoff N, Tang JM, Altman DS. Dental caries patterns and oral health behaviors in Arizona infants and toddlers. Community Dent Oral Epidemiol 2001;29:14-22.

2. Yiu CK, Wei SH. Management of rampant caries in children. Quintessence Int 1992;23:159-68.

3. Stewart RE, Barber TK, Troutman KC, Wei SH. Pediatric Dentistry-Scientific Foundations and Clinical Practice. St. Louis: CV Mosby Co.; 1982. p. 917-26.

4. Seminario AL, Ivancaková R. Early childhood caries. Acta Medica (Hradec Kralove) 2003;46:91-4.

5. de Souza AL, Leal SC, Bronkhorst EM, Frencken JE. Assessing caries status according to the CAST instrument and WHO criterion in epidemiological studies. BMC Oral Health 2014;14:119.

6. Schroth RJ, Brothwell DJ, Moffatt ME. Caregiver knowledge and attitudes of preschool oral health and early childhood caries (ECC). Int J Circumpolar Health 2007;66:153-67.

7. World Health Organization. Oral Health Surveys: Basic Methods. Geneva, Switzerland: World Health Organization; 2013.

8. Frenkel H, Harvey I, Needs K. Oral health care education and its effect on caregivers' knowledge and attitudes: A randomised controlled trial. Community Dent Oral Epidemiol 2002;30:91-100.

9. Jose B, King NM. Early childhood caries lesions in preschool children in Kerala, India. Pediatr Dent 2003;25:594-600.

10. Chan SC, Tsai JS, King NM. Feeding and oral hygiene habits of preschool children in Hong Kong and their caregivers' dental knowledge and attitudes. Int J Paediatr Dent 2002;12:322-31.

11. Casamassimo PS, Thikkurissy S, Edelstein BL, Maiorini E. Beyond the $\mathrm{dmft}$ : The human and economic cost of early childhood caries. J Am Dent Assoc 2009;140:650-7.

12. Prakash P, Subramaniam P, Durgesh BH, Konde S. Prevalence of early childhood caries and associated risk factors in preschool children of urban Bangalore, India: A cross-sectional study. Eur J Dent 2012;6:141-52.

13. Hallett KB, O'Rourke PK. Social and behavioural determinants of early childhood caries. Aust Dent J 2003;48:27-33.

14. Livny A, Assali R, Sgan-Cohen HD. Early childhood caries among a Bedouin community residing in the eastern outskirts of Jerusalem. BMC Public Health 2007;7:167.

15. Schroth RJ, Moore P, Brothwell DJ. Prevalence of early childhood caries in 4 Manitoba communities. J Can Dent Assoc 2005;71:567.

16. Kim Seow W. Environmental, maternal, and child factors which contribute to early childhood caries: A unifying conceptual model. Int J Paediatr Dent 2012;22:157-68.

17. Wolfe GR, Stewart JE, Hartz GW. Relationship of dental coping beliefs and oral hygiene. Community Dent Oral Epidemiol 1991;19:112-5

18. Petersen PE, Hadi R, Al-Zaabi FS, Hussein JM, Behbehani JM, Skougaard, MR, et al. Dental knowledge, attitudes and behavior among Kuwaiti mothers and school teachers. J Pedod 1990;14:158-64

19. Wyne AH, Al-Ghorabi BM, Al-Asiri YA, Khan NB. Caries prevalence in Saudi primary schoolchildren of Riyadh and their teachers' oral health knowledge, attitude and practices. Saudi Med J 2002;23:77-81. 